\title{
Brasil em obras, peões em luta, sindicatos surpreendidos
}

Brazil under Construction, Pedestrians in Revolt, Unions Surprised

Brésil en chantier, travailleurs du bâtiment en lutte, syndicats dépassés

\section{Roberto Véras}

\section{OpenEdition}

\section{Journals}

Edição electrónica

URL: http://journals.openedition.org/rccs/5559

DOI: $10.4000 /$ rccs. 5559

ISSN: 2182-7435

\section{Editora}

Centro de Estudos Sociais da Universidade de Coimbra

Edição impressa

Data de publição: 1 Maio 2014

Paginação: 111-136

ISSN: 0254-1106

\section{Refêrencia eletrónica}

Roberto Véras, "Brasil em obras, peões em luta, sindicatos surpreendidos », Revista Crítica de Ciências Sociais [Online], 103 | 2014, colocado online no dia 26 maio 2014, criado a 01 maio 2019. URL : http:// journals.openedition.org/rccs/5559; DOI : 10.4000/rccs.5559 


\section{ROBERTO VÉRAS}

\section{Brasil em obras, peões em luta, sindicatos surpreendidos}

O presente artigo aborda as revoltas e greves ocorridas em março de $2011 \mathrm{em}$ canteiros de obras do Programa de Aceleração do Crescimento (PAC), do Governo Federal, que alcançou grande repercussão nacional. Tem como foco os conflitos e as negociações, envolvendo trabalhadores, sindicatos, empresários, Governo, Justiça, Ministério Público do Trabalho, entre outros atores, estabelecidos durante a construção das Usinas Hidroelétricas de Jirau e Santo Antônio, situadas no Norte do país. Visou identificar as posições dos referidos atores e, sob uma perspectiva sociológica, propor reflexões sobre as potencialidades e os limites da atividade sindical. Que questões trouxeram tais acontecimentos ao sindicalismo, quanto às relações deste, de um lado, com suas próprias bases e, de outro, com o atual projeto governamental?

Palavras-chave: construção civil; greves; Programa de Aceleração do Crescimento (PAC); revoltas; sindicalismo.

\section{Introdução}

O Brasil conseguiu contornar bem, em termos macroeconômicos, especialmente os primeiros impactos da atual crise global. Sob os efeitos desta, países de capitalismo mais desenvolvido têm visto acelerar-se um processo iniciado nos anos 1970, de persistente desgaste do Welfare State (algo indicado, desde há muito, por exemplo, por Offe, 1984). O Brasil também sofreu as consequências da reestruturação produtiva, da liberalização da economia, das privatizações, sobretudo nos anos 1990 (Pochmann, 2001). Entretanto, com a eleição de Lula para a Presidência da República, em 2003, passaram a ocorrer inflexões socioeconômicas frente às tendências anteriores. Entre final de 2009 e começo de 2010, por efeito da eclosão da crise global, as novas tendências foram interrompidas, com a economia apresentando rápida recuperação, embora nos últimos anos tenha voltado 
a dar sinais de desaceleração. ${ }^{1}$ Diante dos primeiros impactos da crise global, no segundo semestre de 2009, as medidas adotadas pelo Governo reforçaram um novo discurso desenvolvimentista, que vinha sendo incorporado desde o final do primeiro mandato de Lula, em 2006. ${ }^{2}$

O emblema maior do novo discurso desenvolvimentista do Governo tem sido o Programa de Aceleração do Crescimento (PAC). Lançado em 2007, estabeleceu como prioridade investimentos em infraestrutura. Naquela ocasião, Lula entregou a sua coordenação à nova Ministra da Casa Civil, Dilma Roussef, escolhida para lhe suceder. O PAC foi o principal instrumento do discurso eleitoral da candidatura de Dilma. O tom desenvolvimentista do segundo mandato de Lula ganhou maior realce com a orientação adotada pelo Governo no enfrentamento dos efeitos da crise mundial, em fins de 2009. ${ }^{3}$

A Era Lula tem sido marcada por simbolismos e paradoxos. Em se tratando de um país com funda tradição autoritária (nos termos de Chauí, 1997), não se pode deixar de registrar o fato inédito de a Presidência da República ter sido ocupada por um operário, sindicalista, fundador de um partido com tradição de esquerda - o Partido dos Trabalhadores - e símbolo da luta pela democratização do país nos anos 1970 e 1980. Ao mesmo tempo, foi uma alargada política de alianças que deu base à candidatura Lula e ao seu Governo. Um campo, assim, contraditório no seu núcleo, tornou-se fértil à constituição de paradoxos. Desde o início, a estratégia adotada pelo Governo foi a de combinar um duplo jogo. Numa mão, buscou fazer concessões imediatas às exigências do mercado, de modo a evitar riscos de uma desestabilização financeira, que por sua vez pudesse comprometer a governabilidade. As indicações nessa direção começaram, no próprio processo eleitoral, com enfáticas declarações do comando da candidatura Lula,

\footnotetext{
${ }^{1}$ Após amargar taxas médias de crescimento de $1,57 \%$ e de $2,50 \%$, respectivamente, entre 1981-1990 e 1991-2000, o Produto Interno Bruto do Brasil variou em 3,61\%, entre 2001-2010, sendo que em 2004 foi de 5,70\%, em 2005 de 3,20\%, em 2006 de 4,00\%, em 2007 de 6,10\%, em 2008 de 5,20\%, em 2009 de - 0,30\% e em 2010 de 7,50\%. Em 2011 e 2012, no entanto, os valores mantiveram-se em patamares abaixo dessa média: de $2,70 \%$ e $0,9 \%$, respectivamente (Banco Central do Brasil, 2013).

2 A emergência de um novo discurso desenvolvimentista no Brasil e na América Latina tem chamado a atenção do campo acadêmico, que começa a produzir interpretações diversas sobre o tema. São exemplos disso Bresser-Pereira (2006); Sicsú et al. (2007); Ridenti (2008); Oliva (2010); Draibe e Riesco (2011); Diniz (2011); Pochmann (2012).

${ }^{3}$ No balanço realizado pelo próprio Governo, ao final de quatro anos do Programa, foi destacado: "O PAC também foi essencial para coibir os impactos da crise financeira que assolou os mercados internacionais em 2008 e 2009. No Brasil, diferentemente da maior parte dos países, o Governo Federal não reduziu investimentos. Ao contrário, o PAC, juntamente com a força do mercado interno, foi capaz de minimizar significativamente os impactos da crise econômica internacional" (Brasil, 2010).
} 
visando por um lado o cumprimento de todos os contratos financeiros do país, a adoção de uma política fiscal e monetária ortodoxa e a aceitação dos termos do acordo com o FMI (geração de superávit primário, metas de inflação, autonomia do Banco Central, etc.). Por outro lado, procurou reunir condições imediatas para sinalizar no sentido do atendimento das demandas sociais. O Programa Fome Zero foi, quanto a isso, a iniciativa de maior destaque naquele primeiro momento (Véras, 2004: 57).

Enredado nessa situação esteve desde sempre o sindicalismo, especialmente os segmentos ligados à Central Única dos Trabalhadores (CUT). ${ }^{4} \mathrm{O}$ desafio foi, de imediato, encarar a situação como uma oportunidade histórica, no sentido de estancar o processo anterior de subtração de direitos sociais e de iniciar a reversão das desigualdades historicamente presentes no país. Apresentaram-se, grosso modo, duas opções: consolidar-se como sujeito político independente, determinado a disputar, sob condições e oportunidades político-institucionais inéditas, os destinos do país; ou creditar ao Governo o fundamental da iniciativa quanto a isso, identificando-se enquanto parte dele. A primeira opção, mais distante do poder real que o sindicalismo brasileiro hoje detém, incorria no risco de contribuir (na medida do seu peso) para desgastar as bases de apoio ao Governo e, assim, jogar por terra uma oportunidade histórica. A segunda opção, por sua vez, trazia o risco de comprometer sua própria representatividade e autenticidade, podendo favorecer a respectiva rotulação enquanto entidades "oficiais", uma situação tanto mais difícil de sustentar quanto mais o Governo viesse a assumir compromissos contraditórios frente às suas reivindicações históricas. O resultado foi a adoção, por parte do ator sindical, de uma estratégia vacilante, ambivalente, que reforçou uma tendência já estabelecida desde antes: a perda de protagonismo político no cenário nacional, ao mesmo tempo em que se manteve presente e atuando sobre este. ${ }^{5}$

A partir de 2004, os indicadores econômicos e sociais passaram a apresentar tendências sistematicamente positivas. Em balanço recente, Krein et al. admitem:

Além dos impactos positivos do aumento progressivo do dinamismo econômico sobre o mercado e as relações de trabalho no Brasil, ao longo dos dois mandatos do Governo Lula, deve-se destacar que as políticas públicas e as lutas e conquistas do movimento sindical foram decisivas para acrescentar melhorias ao mercado de trabalho brasileiro. $\mathrm{O}$ crescimento da formalização refletiu não somente os impactos

\footnotetext{
${ }^{4}$ Para uma reconstituição da trajetória do "novo sindicalismo", dos anos 1970 até começos dos anos 2000, ver por exemplo, Véras (2011).

5 Ver, a título de um balanço do sindicalismo na Era Lula, Araújo e Véras (2011).
} 
positivos do crescimento, mas também a importância das políticas de regulação do trabalho. Ocorreu uma intensificação do combate ao trabalho forçado e redução expressiva do trabalho infantil - considerando também sua relação virtuosa com o programa Bolsa Família. O salário mínimo ganhou impulso com a campanha conjunta das centrais sindicais em torno de uma política de valorização do salário mínimo, ganhando aliados no Governo que se comprometem com uma política de aumento do mínimo negociada com o movimento sindical, que resultou numa elevação do poder de compra de mais de 50\%, entre 2003 e 2010. (2011: 52)

Com o PAC e o novo discurso desenvolvimentista, o Governo Lula se fortaleceu, conquistou o segundo mandato e, na sequência, elegeu Dilma Roussef como sua sucessora. O Brasil, "em obras", consolidava sua posição como economia "emergente".

Foi sob tais condições que irromperam as lutas de milhares de peões ${ }^{6} \mathrm{da}$ construção civil atuantes em obras do PAC, na forma de revoltas e paralisações, em março de 2011. Que significados tiveram tais acontecimentos? Que questões trouxeram ao sindicalismo, especialmente quanto às relações deste, de um lado, com suas próprias bases e, de outro, com o atual projeto governamental? Que perspectivas apontam quanto ao futuro do sindicalismo no Brasil? Este artigo pretende reconstituir os acontecimentos acima referidos, com foco nos casos relacionados às obras de construção das Usinas Hidroelétricas (UHE) de Jirau e Santo Antônio, ambas situadas no rio Madeira, no estado amazônico de Rondônia. Com base em informações e depoimentos dos principais atores envolvidos nos acontecimentos, veiculados pela mídia e por sítios, portais, blogues e outros meios, mantidos por órgãos públicos, instituições da sociedade civil, empresas, entidades sindicais, entre outros, nos propomos a identificar os sentidos em disputa e levantar algumas reflexões sobre a atuação sindical no contexto atual.

\section{O PAC e as Usinas Hidroelétricas de jirau e Santo Antônio O PAC trocado em miúdos}

O PAC foi lançado, pelo Governo Federal, em 2007, no ato da posse de Lula para seu segundo mandato. Entendia-se que os ajustes dos primeiros quatro anos e um contexto internacional favorável propiciariam as bases para uma retomada do crescimento econômico com distribuição de renda. O Governo incorporou o pressuposto desenvolvimentista do papel indutor do Estado,

\footnotetext{
${ }^{6}$ Não se sabe precisamente onde e quando a expressão peão passou a ser usada, no Brasil, com o sentido de operário pouco qualificado ou sem qualificação. Um dos primeiros estudos a incorporar o termo com tal conotação foi o de Rainho (1980).
} 
mas ao mesmo tempo o circunscreveu aos limites ditados pelos compromissos macroeconômicos. Na síntese de Pêgo e Campos Neto (2008: 07), o PAC se pautou pelos seguintes propósitos principais: "i) investimento em infraestrutura; ii) estímulo ao crédito e ao financiamento; iii) melhora do ambiente de investimento; iv) desoneração e aperfeiçoamento do sistema tributário; e v) medidas fiscais de longo prazo", acrescentando que "seus fundamentos econômicos estão baseados na estabilidade monetária, responsabilidade fiscal e baixa vulnerabilidade externa". Sobretudo, por meio de investimentos em infraestrutura, o Governo visou aumentar a produtividade das empresas, estimular investimentos privados, gerar emprego e renda e reduzir as desigualdades regionais. Até o final de 2010, segundo dados oficiais, foram investidos mais de $\mathrm{R} \$ 600$ bilhões, oriundos do Governo Federal, de empresas estatais e do setor privado, com destaque para os setores de energia, transporte, habitação, saneamento, recursos hídricos. Foram incluídas obras de grande envergadura, como as Usinas Hidroelétricas de Jirau e Santo Antônio, em Rondônia, a Usina Termelétrica de Pecém, no Ceará, a Transposição do Rio São Francisco e a construção da Ferrovia Transnordestina, no Nordeste, a Refinaria da Petrobrás, em Pernambuco. Foram, também, contemplados programas de impacto social, como o "Minha Casa Minha Vida" e o "Luz para Todos", respectivamente nos setores de habitação e de distribuição de energia elétrica. Ainda segundo os dados oficiais, a participação do investimento total no PIB passou de 16,4\% em 2006, para 18,4\% em 2010 (Brasil, 2010). Em março de 2010, o Governo lançou o PAC 2, visando dar continuidade aos mesmos eixos estruturantes da versão anterior (Brasil, 2012).

De várias ordens têm sido, nesses anos, as críticas ao PAC. Para uns, foram incluídas nessa conta muitas ações antes previstas por ministérios e estatais, ao mesmo tempo em que essas se encontram desconectadas de outras ações estratégicas do Governo nos campos econômico e institucional, imprimindo um caráter mais emergencial do que de longo prazo às medidas (Kupfer, 2007). Outros argumentam que as obras concorrem sobretudo para reforçar o setor de exportação de commodities (Leitão, 2009). Há quem sugira que os investimentos destinados ao PAC subtraem recursos das Políticas Sociais (Rodrigues e Salvador, 2011). Queixas passaram sistematicamente a ser veiculadas, principalmente na grande mídia, quanto ao ritmo das obras (a exemplo de O Globo, 2012).

\section{As Usinas de Jirau e Santo Antônio}

A construção das UHE de Jirau e Santo Antônio, às margens do rio Madeira, em Rondônia, iniciadas respectivamente em 2008 e 2009, estão entre as maiores obras do PAC. Juntas, preveem capacidade instalada de 
6,5 mil MW. Enquanto a UHE de Santo Antônio dista $7 \mathrm{~km}$ de Porto Velho, capital de Rondônia, a UHE de Jirau se encontra a $120 \mathrm{~km}$ da capital. Em 2011 contavam, juntas, com mais de 40 mil trabalhadores envolvidos em sua construção. Ambas integram um plano de exploração do potencial energético dos rios da Amazônia, que inclui a construção da UHE de Belo Monte, Pará, entre outras. O custo total previsto para as duas obras foi calculado em cerca de R $\$ 24$ bilhões. A UHE de Jirau pertence ao Consórcio Energia Sustentável do Brasil (ESBR) (composto pela Suez Energy, com $50,1 \%$ do capital, além da Eletrosul, com 20\%, a Chesf, com $20 \%$ e a Camargo Corrêa, com 9,9\%) e sua construção ficou a cargo da Camargo Corrêa. A construção da UHE Santo Antônio, de propriedade do Consórcio Santo Antônio Energia S.A. (Odebrecht, com 18,6\%; Construtora Andrade Gutierrez S.A., com 12,4\%; Furnas, com 39\%; Cemig, com 10\% e FIP, com 20\%), ficou a cargo da Odebrecht (Brasil, 2010). ${ }^{7}$

De importância nacional, esses empreendimentos vêm trazendo também fortes impactos socioeconômicos locais. Desde a concepção, têm gerado controvérsias sociais e ambientais. Foi em torno da concessão da licença ambiental para o início das obras, em 2008, que a então Ministra do Meio Ambiente, Marina Silva, entrou em conflito com o Governo, abandonou o cargo e abandonou o Partido dos Trabalhadores. Conflitos têm ocorrido entre as populações atingidas e as empresas, inclusive com ações impetradas judicialmente por aquelas, acusando essas pelo uso de violência nos despejos (Isto É Brasil, 2011). ${ }^{8}$

O setor da construção civil tem a marca da heterogeneidade, compreendendo, entre outros, subsetores como edificações, montagem industrial e construção pesada, sendo neste último caso onde se situam as obras de infraestrutura, a exemplo da construção de hidroelétricas. Entretanto, não obstante as diferenças (de porte, de logística, de padrão de gestão, etc.), o setor, que é um grande empregador de mão de obra no país, tem em comum um perfil historicamente marcado pelo trabalho precário. Conforme atestam estudos como Farah (1996), DIEESE (2001), Cockell (2008), Cockell e Perticarrari (2010) e Costa (2013), são características de

\footnotetext{
${ }_{7}$ Para mais informação ver http://www.santoantonioenergia.com.br/site/portal_mesa/pt/home/home. aspx (UHE Santo Antônio) e http://www.energiasustentaveldobrasil.com.br/ (UHE Jirau).

8 A ocupação da Amazônia por meio de grandes projetos estatais e privados, a começar pelos empreendimentos de "colonização", remonta às décadas de 1960 e 1970, no contexto da ação desenvolvimentista e integradora patrocinada pelo Regime Militar. As lutas de resistência, contra empresas e governos, desencadeadas por índios, camponeses e trabalhadores, de diversos modos atingidos pelos referidos projetos, desde sempre fizeram parte desse processo (ver, por exemplo, estudo de Esterci, 1987).
} 
destaque: baixa remuneração; elevada rotatividade (em razão do caráter cíclico da atividade e das estratégias empresariais); predomínio de baixa escolaridade e qualificação; alto grau de informalidade; subcontratações sucessivas (intensificadas com a reestruturação produtiva) ; ${ }^{9}$ agenciamento de mão de obra através de "gatos", ${ }^{10}$ intensificação do trabalho pelo domínio do regime de remuneração de acordo com a produtividade e recurso excessivo a horas extra; altos índices de acidentes de trabalho e de doenças ocupacionais; em síntese, verificamos que prevalece a instabilidade (Costa, 2013).

O município de Porto Velho, em 2010, tinha quase 430 mil habitantes (IBGE, 2011). A infraestrutura da região metropolitana foi sempre deficiente, o que potencializou o impacto das obras. A chegada de milhares de trabalhadores ${ }^{11}$ à região tem gerado enorme pressão sobre a capacidade ali instalada de serviços públicos e privados - saúde, saneamento básico, habitação, segurança pública, entre outros (Moret e Guerra, 2009). Às condições de trabalho precárias, nos canteiros de obras, associaram-se condições de vida inseguras na cidade de Porto Velho e entorno.

\section{Os acontecimentos e seus sentidos em disputa}

\section{Eclodem revoltas e paralisações em jirau e Santo Antônio ${ }^{12}$}

No dia 15 de março de 2011, uma briga entre um operário e um motorista de uma das subcontratadas da Camargo Corrêa foi o estopim de uma revolta

\footnotetext{
9 A atuação sindical no setor da construção civil no Brasil tem tido nos processos de terceirização um desafio especial. Segundo Cockell e Perticarrari (2010: 635), embora tais práticas tenham como uma motivação a busca de serviços especializados, visam sobretudo reduzir custos trabalhistas, quando são subcontratadas empresas arregimentadoras de mão de obra, do tipo "gatos". As subcontratações podem levar a processos sucessivos, quando subcontratadas subcontratam outras empresas. As condições de trabalho se diferenciam ao longo dessa cadeia.

${ }^{10}$ Designação comum no Brasil para arregimentador de mão de obra que atua como intermediário junto, principalmente, a empresas rurais e da construção civil. "Em grande parte da literatura e do folclore sobre mão de obra volante, essa figura é identificada com a de um indivíduo que explora os trabalhadores, na medida em que se apropria de parte de sua remuneração" (Aguirre e Bianchi, 1989: 39).

${ }^{11} \mathrm{Na}$ sua maioria, os trabalhadores de grandes obras como essas são "trecheiros". Para Guedes (2011: 182), a origem dos termos "trecho" e "trecheiro" pode ter tido relação com a prática de divisão, entre empreiteiras, do serviço referente a uma grande obra de construção de estrada, em "trechos". Em trabalhos mais recentes o termo "trecheiro" teria passado a ser usado com um sentido alargado, como "intinerante". Guedes propõe que a noção se estabeleça em contraste com a de "migrante", cujo "trajeto se justifica pelo ponto que está em seu fim", enquanto para o primeiro "a circulação é um objetivo em si mesmo". Nesse enquadramento inclui os "peões de obra". Ver a este respeito também Fontes (2003).

${ }^{12}$ A mídia local e nacional noticiou amplamente os acontecimentos que serão narrados a seguir. Para a reconstituição dos fatos, nos baseamos em ampla pesquisa nos principais jornais e revistas nacionais (revistas Isto É, Veja, Época, Carta Capital e Caros Amigos; jornais Folba de São Paulo, $O$ Estado de São Paulo e $O$ Globo). Utilizamo-nos ainda de consultas a sítios sindicais, governamentais, blogues de jornalistas, entre outras fontes midiáticas.
} 
dos peões da construção da UHE de Jirau. O fato fez explodir uma situação de tensão latente, dadas as condições de trabalho ali vigentes. A revolta, com destruições de alojamentos, escritórios, ônibus, pontos comerciais e outros prédios e equipamentos, estendeu-se até à madrugada do dia 16, quando chegou ao local a Polícia Militar e a Força Nacional de Segurança. A repercussão na mídia foi imediata, favorecendo uma onda de mobilizações em outras obras do PAC, que ganhou amplitude nacional.

As obras de Jirau e Santo Antônio foram suspensas pelas construtoras e os trabalhadores foram dispensados temporariamente. Estes, cerca de 20 mil em Jirau e 16 mil em Santo Antônio, começaram a deixar os canteiros. A maioria se destinou a Porto Velho, de modo a aguardar pela normalização da situação ou a tentar retornar para seus estados de origem. Outros permaneceram no entorno das obras, em abrigos improvisados.

Assim se tornaram públicas as queixas dos operários dessas obras, acusando péssimas condições de trabalho, com destaque para longo tempo para as "baixadas"; ${ }^{13}$ atuação de "gatos"; adoção, nos canteiros, do sistema de "barracão"; ${ }^{14}$ precariedade dos alojamentos; incidência de doenças (como malária); salários e condições de trabalho diferenciados com a disseminada prática de subcontratações; burla da legislação do trabalho e dos acordos coletivos (informalidade, manipulação de informações sobre acidentes de trabalho, atrasos no pagamento, calotes); relações autoritárias de trabalho (com abusos, humilhações, castigos); pressões para o aumento do ritmo de trabalho.

Um clima de tensão tomou conta da região. Muitos operários de ambas as obras, instalados em abrigos improvisados, passaram a bloquear a rodovia BR-364. Além das queixas sobre condições de trabalho, dirigiram-se às empresas cobrando transporte para retornarem às suas cidades. No dia 22 de março, a Odebrecht decidiu retomar a obra de Santo Antônio, mas o Sindicato dos Trabalhadores na Indústria da Construção Civil (STICCERO) convocou uma assembleia, visando definir uma pauta de reivindicações para negociar com as empresas. A paralisação das obras de Jirau e Santo Antônio foi então mantida, por decisão dos trabalhadores, até o dia 25 de março. A volta ao trabalho ocorreu com a promessa de as empresas retomarem as negociações. Entre as reivindicações propostas, destacaram-se: "baixadas" dez dias a cada três meses (ao invés de cinco dias a cada quatro meses);

\footnotetext{
13 Períodos de folgas para visitas a familiares, por parte dos "trecheiros".

14 Prática comum em áreas rurais do Nordeste e de outras regiões do país, que obriga moradores e assalariados a comprar bens de primeira necessidade em unidades comerciais mantidas pelos proprietários/empregadores. Ver, por exemplo, Heredia (1989).
} 
mudanças nos planos de saúde e na gestão do vale-refeição; melhores condições de segurança, entre outras.

As demandas dos trabalhadores de Jirau e Santo Antônio, escancaradas com as revoltas e paralisações, foram assim sendo canalizadas para os processos institucionalizados de negociação social e sindical.

\section{Diante das repercussões, imediatamente os atores se (re)posicionam}

Os consórcios proprietários das duas usinas, tão logo eclodiram as revoltas, manifestaram-se por meio da mídia, de modo a esvaziar qualquer justificativa social para os acontecimentos. Nomearam estes como "manifestações isoladas" e "atos de vandalismo", argumentando que, da parte dos trabalhadores, não se constituíram nem lideranças nem reivindicações. Nas palavras do presidente do Consórcio ESBR, Victor Paranhos, "A grande questão é que a gente teve uma reunião com o sindicato da construção civil e eles dizem que não têm nada a ver com isso. Eles não tinham nenhuma reivindicação” (Folha.com, 2011a). Já o presidente da Camargo Corrêa, Antônio Marques, insinuou: "eu não concebo que uma briga entre um motorista de ônibus e um empregado embriagado possa motivar a queima de mais de 40 ônibus. Não se faz isso com palito de fósforo e isqueiro, é preciso ter combustível preparado para isso" (Isto É Brasil, 2011). Ao mesmo tempo, as empresas disseram-se, desde sempre, abertas ao diálogo (Rondoniagora.com, 2011). Os responsáveis pelos empreendimentos anunciaram, também, uma preocupação com um possível atraso no cronograma das obras. Assim sinalizavam com uma pressão junto ao Governo.

Da parte do Governo Federal, as posições foram diversas. O Banco Nacional de Desenvolvimento Econômico e Social (BNDES), por exemplo, anunciou que iria manter os repasses do empréstimo às obras em conflito. As UHE de Jirau e Santo Antônio contam com R\$13,3 bilhões de financiamento dessa instituição, correspondendo a $63 \%$ e $64 \%$ do custo total de cada uma, respectivamente (Isto É Dinheiro, 2011). Quanto à Presidência da República, imediatamente enviou a Força Nacional de Segurança para a região e, na outra mão, designou o Secretário-Geral da Presidência, Gilberto Carvalho, para conduzir as negociações. Seu primeiro ato foi convocar as empresas e as centrais sindicais para uma primeira reunião. Ao que tudo indica o Governo se surpreendeu com as revoltas, por não estar atento às insatisfações dos operários das obras do PAC.

Quanto ao Ministério Público Federal, abriu inquérito para apurar se havia violações de direitos humanos em Jirau. A Justiça do Trabalho constituiu uma vara itinerante na localidade para receber as demandas dos trabalhadores. No dia 19, concedeu uma liminar, em favor do Ministério 
Público do Trabalho, obrigando as empreiteiras ao fornecimento de "transporte (aéreo ou terrestre), sem ônus para os empregados recrutados fora de Porto Velho que optarem em retornar aos seus locais de origem" (MPT, 2011).

O Prefeito de Porto Velho, Roberto Sobrinho, do PT, manifestou preocupação com a interrupção das obras, dizendo-se apreensivo com a concentração de trabalhadores nas imediações da capital e insinuando a existência de uma ação organizada por trás dos acontecimentos: "Não é algo espontâneo. Tem pessoas bem organizadas" (Folha.com, 2011b). Nesses termos, se aproximou mais do discurso das empresas do que da perspectiva dos revoltosos.

Os trabalhadores, em relatos diretamente captados pela mídia ou por meio de depoimentos tomados pelo Ministério Público e entidades sindicais, acusaram abusos nos métodos de gestão, inclusive com violência física; regime de "barracões"; burla da legislação trabalhista e dos acordos coletivos; desfasamento de salários; exposição a doenças; poucas folgas periódicas concedidas aos trabalhadores para visita às respetivas famílias, as chamadas "baixadas". Nas palavras de um deles: "queremos que a cada 90 dias que passamos aqui a empresa forneça passagem aérea para que a gente fique ao menos um pouco com a família. Hoje recebemos passagem de ônibus e eu, por exemplo, que moro no Maranhão, demoro cinco dias para chegar em casa. Praticamente vejo meus filhos e já preciso voltar" (CUT Brasil, 2011a).

O STICCERO divulgou a seguinte nota:

O STICCERO vem a público manifestar sua preocupação com a grave situação ocorrida na Usina de Jirau nesta semana, que resultou em violência e depredação. O STICCERO esclarece que os fatos ocorridos não resultaram de uma ação sindical e trabalhista, até porque o Sindicato e os trabalhadores sempre atuaram de forma organizada e pacífica para conquistar e ampliar os direitos da categoria. O Sindicato estará atuando junto às empresas e autoridades visando garantir salários, manutenção de empregos e o retorno temporário de trabalhadores aos seus locais de origem; bem como a retomada da obra tão logo sejam garantidas condições adequadas de segurança e trabalho. Porto Velho-RO, 18 de março de 2011. Raimundo Soares da Costa Presidente. (O Rondinense, 2011)

Evidencia-se o cuidado do Sindicato em ter sua imagem associada aos conflitos, ao mesmo tempo em que afirma o seu compromisso em intermediar as negociações com as empresas. $\mathrm{O}$ ambiente sindical local vinha sendo marcado por forte disputa. O STICCERO, criado em 1986 e filiado 
à CUT em 2009 (com a posse da chapa de oposição), acusou, junto à Justiça do Trabalho, o Sindicato dos Trabalhadores nas Indústrias da Construção Pesada de Porto Velho (SINTRAPAV-RO), criado em 2008 e ligado à Força Sindical (FS), de ter tido participação no incitamento às revoltas. Ambos disputavam o direito de representação dos trabalhadores de Jirau e de Santo Antônio. Em fins de 2010, o STICCERO havia conseguido junto à Justiça do Trabalho a proibição de o SINTRAPAV praticar "atos em nome da categoria".

Segundo alegou o então presidente da CUT em âmbito nacional, Artur Henrique, "há dois anos a CUT avisava que poderia haver problemas, queríamos contrapartidas sociais para que essas obras fossem realizadas" (Isto É Brasil, 2011). Quanto à FS, o seu presidente, deputado federal Paulinho da Força, declarou: "É a maior paralisação desde as greves do ABC, em 1980. Depois das greves do Lula, nunca mais houve tantos trabalhadores parados" (UOL Notícias, 2011b). Em nota oficial, a FS assim se posicionou: "não podemos permitir que trabalhadores vivam, ainda, em situação análoga à escravidão no País” (CNTM, 2011).

Já o Movimento dos Atingidos por Barragens (MAB) assumiu, em nota, a seguinte posição, sinalizando para uma convergência de perspectiva entre os "atingidos" e os "peões":

As empresas construtoras de Jirau são as mesmas que foram denunciadas em recente relatório de violação de Direitos Humanos, aprovado pelo Governo Federal, que constatou que existe um padrão de violação dos direitos humanos em barragens e de criminalização, sendo que 16 direitos têm sido sistematicamente violados na construção de barragens. Os atingidos por barragens e os operários têm sido as principais vítimas [...] Em junho de 2010, o MAB já havia alertado a sociedade que em Jirau havia indícios e denúncias, que circularam na imprensa local, de que as empresas donas da Usina de Jirau haviam contratado ex-coronéis do Exército para fazer uma espécie de trabalho para os donos da usina de Jirau e não seria surpresa se estes indivíduos contratados pelas empresas promovessem ataques ou sabotagens contra os operários e atingidos, para jogar uns contra os outros e/ou criminalizar nossas organizações e sindicatos [...] Em 2011, o MAB completa 20 anos de luta e os atingidos comemoram a resistência nacional, mas também denunciam que estas empresas não têm compromisso com a população atingida e nem com seus operários. Recebem altas taxas de lucro que levam para seus países e o povo da região fica com os problemas sociais e ambientais. O MAB vem a público exigir o fim da violação dos direitos humanos em barragens e esperamos que as reivindicações por melhores condições de trabalho e vida dos operários sejam atendidas. Água e energia não são mercadorias! (MAB, 2011) 
Outras mobilizações nas obras do PAC definem o caráter nacional dos acontecimentos As revoltas e paralisações de Jirau e Santo Antônio repercutiram de imediato por todo o país, particularmente entre os trabalhadores das grandes obras do PAC. Em levantamento feito pelo Departamento Intersindical de Estatística e Estudos Socioeconômicos (DIEESE), no início de abril (UOL Notícias, 2011b), foi estimado em 170 mil o número de trabalhadores paralisados na construção civil em todo o país nesse período.

\section{QUADRO 1 - Paralisações na construção civil em março}

\begin{tabular}{lcc}
\hline \multicolumn{1}{c}{ Obra/local } & Duração & Grevistas \\
\hline UHE de Jirau (Rondônia) & Desde $15.03^{*}$ & 22000 \\
\hline UHE de Santo Antônio (Rondônia) & Desde $18.03^{*}$ & 16000 \\
\hline UHE de São Domingos (Mato Grosso do Sul) & Desde $24.03^{*}$ & 3000 \\
\hline Obras na Bahia & 36 dias & 80000 \\
\hline Termoelétrica de Pecém (Ceará) & 10.02 a 01.03 & 6000 \\
\hline Petroquímica Suape (Pernambuco) & 11 dias & \\
\hline Refinaria Abreu e Lima (Pernambuco) & 15.03 a 25.03 & 14000 \\
\hline
\end{tabular}

Fonte: DIEESE

*Até 04.04.2011, quando o referido levantamento foi publicado, estes movimentos grevistas não tinham tido ainda um desfecho, o que só veio a ocorrer ao longo de abril.

Em geral, segundo a mesma fonte, as reivindicações se relacionavam a condições precárias de trabalho como reajuste salarial, melhora na estrutura dos alojamentos, pagamento de horas extra, condições de "baixada", equalização de direitos entre contratantes e subcontratadas, planos de saúde, cumprimento da legislação trabalhista e acordos coletivos. Diante da contundência das mobilizações, foram estabelecidos processos de negociação direta com as empresas e com as entidades sindicais, em geral passando a atuar como mediadoras após a eclosão dos protestos. Em vários casos, a Justiça do Trabalho decretou as greves como "ilegais", por não cumprirem os procedimentos legalmente exigidos (em Suape e em Pecém, por exemplo). 


\section{Quando a negociação nacional se associa à local a mediação sindical ganha relevo}

Com as repercussões dos acontecimentos na mídia nacional, a CUT e a Confederação Nacional dos Sindicatos dos Trabalhadores da Construção Civil e da Madeira (CONTICOM), àquela filiada, passaram a atuar junto ao STICCERO, visando negociar, emergencialmente, uma melhoria nas condições de trabalho nos canteiros e, na sequência, dar impulso à campanha salarial. Vagner Freitas, Diretor da CUT Nacional, e representante desta nas negociações locais, anunciou em sua chegada a Porto Velho: “a CUT entende que não há crescimento sem trabalho decente, condições dignas e diálogo. $\mathrm{O}$ que vinha acontecendo em Rondônia era muito grave e por isso resolvemos intervir no processo de negociação" (CUT Brasil, 2011a) e, também: "ao lado do Sticcero, trabalhamos para reunir a base e fechar os pontos da pauta que nortearão a campanha salarial" (CUT Brasil, 2011b). Uma série de reuniões passou a ocorrer envolvendo sindicalistas, comissões de operários eleitos pela categoria, o Ministério Público e as empresas responsáveis. Assembleias realizadas nas obras acompanharam as negociações. De imediato foi conquistada permissão para os sindicalistas visitarem os canteiros e algumas demandas econômicas foram atendidas. Conforme o presidente do STICCERO: “conseguimos com que nossos companheiros continuassem recebendo enquanto aguardam nos locais onde moram a melhoria nas condições de trabalho. A empresa se comprometeu a pagar os salários e apresentar os comprovantes ao sindicato" (ibidem). O que mais chamou a atenção dos sindicalistas nas visitas às obras foram os problemas gerados com as subcontratações. Conforme Freitas, "havia até mesmo um processo de quarteirização, quando as terceirizadas passam o serviço para outra empresa” (CUT Brasil, 2011c).

Permearam ainda as negociações uma cobrança, por parte dos sindicalistas, no sentido de essas obras incorporarem metas de responsabilidade social. Emergiu, assim, um questionamento sobre o papel das hidroelétricas no desenvolvimento local. Para Freitas: "construções como essas exigem planejamento e investimento nos serviços públicos para adequar a segurança, a educação, a habitação, o transporte à quantidade de pessoas que chegam" (CUT Brasil, 2011d). Evidenciou-se uma preocupação por parte dos moradores da região quanto a um novo impacto com a conclusão das obras: "o que vai acontecer quando terminarem as usinas e o pessoal for embora?” (Carta Capital, 2011b). São questões que, na euforia dos impactos econômicos e de geração de empregos, trazidos pelas obras, passaram ao largo, mesmo da agenda sindical.

Estiveram também presentes nas preocupações sindicais as disputas entre o STICCERO e o SINTRAPAV. Freitas, por exemplo, logo após uma 
reunião entre empresas, sindicalistas, Ministério do Trabalho e Ministério Público, declarou: "a audiência desta noite teve um aspecto muito importante, que é o fato de o Ministério do Trabalho e a empresa terem deixado muito claro quais são as entidades sindicais que realmente representam esses trabalhadores" (CUT Brasil, 2011j).

Em outra frente, as Centrais Sindicais obtiveram do Governo Federal o compromisso com uma agenda nacional de negociações, envolvendo o conjunto das obras do PAC, com empresários, Governo e sindicalistas. Visavam firmar um acordo nacional com regras para o setor e com o compromisso de maiores investimentos governamentais e empresariais em qualificação profissional. Nas palavras do presidente da CUT:

Estamos cobrando medidas de garantia do trabalho decente, as contrapartidas sociais, em todas as obras e projetos financiados por dinheiro público, há vários anos. Nós precisamos estabelecer mecanismos eficazes, como fiscalização permanente e punição severa para as empresas que tomam dinheiro público emprestado mas que não respeitam os direitos dos trabalhadores, não respeitam a representação sindical. (CUT Brasil, 2011b)

E, ainda, a mesma central:

Estamos reivindicando, portanto, que o governo estabeleça, de imediato, um grupo de trabalho envolvendo os ministérios da Fazenda, do Trabalho e do Planejamento e a Secretaria-Geral da Presidência da República, com as centrais sindicais e com as confederações empresariais, para se estabelecer um processo de discussão permanente sobre temas que interessam aos trabalhadores, aos empresários e ao governo nas questões das grandes obras de infraestrutura do país. (UOL Notícias, 2011a)

Uma posição convergente foi apresentada pela FS. Para o seu presidente, "a ideia é fazer um acordo nacional que padronize os salários dos operários de obras do PAC e criar uma comissão tripartite envolvendo governo, sindicatos e empresas para fiscalizar as condições de trabalho nas obras" (Veja, 2011).

$\mathrm{Na}$ perspectiva sindical, o que mais interessava era ser reconhecido como interlocutor legítimo em um processo de negociação social, um aspecto por demais destoante da cultura política e empresarial brasileira e, mais em particular, de setores como o da construção civil, com baixa tradição sindical. A proposição central foi a de um acordo nacional para o setor, com garantias trabalhistas e sociais mínimas. Na hipótese de as empresas desrespeitarem o acordado, o Governo deveria suspender os financiamentos públicos 
dos empreendimentos em questão. Quanto ao Governo, sobretudo visou estancar a onda de tumultos e paralisações, de modo a não comprometer os cronogramas das obras e a sua própria imagem social. Dos sindicalistas, buscou o compromisso de que as disputas entre as centrais não viessem a alimentar os conflitos nos canteiros. Das empresas, suscitou a garantia de concessões básicas, quanto às condições de trabalho vigentes nas obras.

A primeira reunião ocorreu no dia 29 de março, com a Secretaria Geral da Presidência e os Ministérios do Trabalho e Emprego e do Planejamento, a Câmara Brasileira da Indústria da Construção (CBIC), o Sindicato Nacional da Indústria da Construção Pesada (SINICON) e as centrais sindicais - CUT; FS; CSP-CONLUTAS $;^{15}$ Central Geral dos Trabalhadores do Brasil (CGTB); Central dos Trabalhadores e Trabalhadoras do Brasil (CTB); União Geral dos Trabalhadores (UGT); Nova Central Sindical de Trabalhadores (NCST). Gilberto Carvalho adiantou-se: "o governo vai entrar firme na tentativa de antecipar crises". E ainda: "Em cada obra importante haverá uma representação. O governo é provocador dessa mesa tripartite" (Blog do Planalto, 2011). O Ministro procurou, por outro lado, realçar o momento de expansão da economia e da oferta de emprego, classificando esse como "um bom problema" (ibidem). Quanto às empresas, apresentaram a versão de que as mobilizações foram minoritárias. Para Paulo Safady, da CBIC, 80 mil trabalhadores envolvidos nas paralisações representavam uma parcela insignificante dos 2,7 milhões da construção civil. Reforçou que a qualidade dos canteiros em geral poderia ser considerada "ótima". Por fim, colocou-se aberto às negociações (UOL Notícias, 2011a).

Resultou da reunião a constituição de uma mesa tripartite permanente de negociações, coordenada pelo Governo. Tal ambiente logo repercutiu em Santo Antônio, onde no dia 31 de março foi firmado um acordo entre o Sindicato e a Odebrecht, que incluía $5 \%$ de antecipação salarial, aumento de $R \$ 110$ para $R \$ 132$ no valor da cesta básica e licença de cinco dias a cada três meses trabalhados, com passagens custeadas pela empresa. Para os sindicalistas, no entanto, a situação continuava incerta. Nas palavras de Freitas, "não é possível que a solução seja regional e individual de cada obra, porque em outros canteiros de outros estados há problemas

\footnotetext{
${ }^{15}$ A CONLUTAS foi criada, sob influência dos militantes do Partido Socialista Unificado dos Trabalhadores (PSTU), em 2004, a partir de uma dissidência da CUT. Em 2010 se constituiu como Central Sindical e Popular - CONLUTAS. Sua atuação se pautou desde sua fundação por uma clara oposição aos Governos Lula e Dilma. No ciclo de greves das obras do PAC de 2011 buscou se projetar como um projeto político-sindical diferenciado da CUT, da FS e das demais centrais, tidas como dependentes do Governo. Entretanto, naqueles acontecimentos de Jirau e Santo Antônio, não conseguiu maior influência.
} 
semelhantes" (CUT Brasil, 2011k). Diante da aprovação da proposta em assembleia, no dia 4 de abril, o então presidente do STICCERO declarou: "iniciamos agora um estado de greve e daremos continuidade à campanha salarial que tem data-base em 1. de maio" (Carta Capital, 2011a). A paralisação em Santo Antônio durou de 18 de março a 4 de abril, sendo de 18 a 25 de março por determinação da empresa (com receio das revoltas) e de 25 de março a 4 de abril por decisão dos trabalhadores. Quanto a Jirau, as resistências da Camargo Corrêa inviabilizaram de imediato que o mesmo acordo fosse ali firmado, o que veio a acontecer apenas no dia 11 de abril. Os trabalhadores voltaram ao trabalho após 26 dias de paralisação. No mesmo dia 11, o STICCERO, a CONTICOM e a CUT realizaram entrevista coletiva em Porto Velho, para apresentar um balanço das negociações e divulgar a pauta de reivindicações da campanha salarial do setor. Nas palavras do presidente do STICCERO: "hoje, tudo o que negociamos trazemos para vocês. Desde 2009, quando assumimos, numa época em que o sindicato fechava acordo de 2 anos sem passar por assembleia e sem a nossa presença, o Sticcero ganhou vida" (CUT Brasil, 2011e).

Os sentidos dos acontecimentos continuavam em disputa. No dia 5 de abril, o STICCERO, a CUT, o MAB e vários sindicatos locais realizaram uma passeata pelas ruas de Porto Velho, em apoio às lutas dos peões das obras e dos "atingidos" pelas barragens. ${ }^{16}$ A campanha salarial dos trabalhadores da construção civil de Rondônia, graças aos acontecimentos de Jirau e Santo Antônio, ocorreu sob um clima de intensa mobilização. Com indicações de greve geral, o sindicato e as empresas chegaram a um acordo, no dia 18 de maio, que visava reajuste salarial de $11 \%$, aumento da cesta básica para $R \$ 170$, pagamento de $70 \%$ de horas extra entre segunda e sábado, sendo aos domingos de $100 \%$, "baixadas" com nove dias, sendo os custos de transporte de responsabilidade das empresas aéreas, estabilidade no emprego pelo período de um ano, entre outros itens. Para Cláudio Gomes, da CONTICOM, "o índice de aumento conquistado em Jirau e Santo Antônio é o maior de Rondônia e superior à média do país" (CUT Brasil, 2011f). Também em maio, a Justiça do Trabalho determinou o STICCERO como "representante da categoria dos trabalhadores da construção civil leve e pesada no Estado de Rondônia", estabelecendo ainda suspensão do registro sindical do SINTRAPAV (CUT Brasil, 2011h).

Em paralelo, foi instalada no front nacional no dia 31 de março uma Comissão Tripartite com o fim de estabelecer os pontos de um acordo

\footnotetext{
${ }^{16}$ Em uma tímida indicação da constituição de uma articulação entre sindicalismo e movimentos sociais (conforme sugerida, por exemplo, por Waterman, 2008).
} 
nacional. Definiu-se como prioridade a substituição dos chamados "gatos" pelo Sistema Nacional de Emprego (SINE), como procedimento de contratação de mão de obra. ${ }^{17}$ No dia 14 de abril ocorreu a segunda reunião da referida Comissão, da qual resultou a criação de uma comissão técnica para elaborar o marco regulatório do acordo. $\mathrm{Na}$ ocasião foram firmados acertos sobre cursos de formação profissional e quanto ao aparelhamento do SINE. No dia 12 de maio, na terceira reunião da Comissão, foram constituídos dois grupos de trabalho - um de saúde e segurança no trabalho e outro de intermediação, contratação e formação de mão de obra. Decidiu-se ainda pela inclusão do ramo da construção civil como um todo nas negociações.

Quatro meses após os conflitos nas obras do PAC, persistiam os problemas nas relações de trabalho pelo menos em Jirau e Santo Antônio. É o que ficou evidenciado com a visita da presidenta Dilma à região, no dia 5 de julho, oficialmente com o objetivo de acionar um dispositivo desviando as águas do rio para as comportas da hidrelétrica, tendo recebido em audiência o STICCERO e o MAB. Ambas as entidades entregaram cartas à presidenta, relatando a permanência das precárias condições de trabalho vigentes nas duas obras. Conforme o Sindicato, até começo de julho foram demitidos por justa causa aproximadamente 6 mil trabalhadores:

Temos mais de 30 ações na Justiça denunciando isso. Alguns sequer sabem que foram demitidos enquanto estavam em casa. Desde os conflitos, a relação com as empresas retrocedeu e aumentou a dificuldade para ter acesso ao canteiro de obras.

(Rondonia Dinâmica, 2011)

Quanto ao MAB, seu coordenador estadual denunciou: "as famílias permanecem sem terra para produzir e o subsídio que a empresa pagava terminou neste mês. Muitos tiveram que pagar contas de água de até $R \$ 150$, ao contrário do que acontecia antes, quando utilizavam os recursos naturais dos rios" (CUT Brasil, 2011i). Dilma, diante das denúncias e demandas dos líderes sindicais e populares, encarregou Gilberto Carvalho de retomar as negociações com as empresas.

\footnotetext{
${ }_{17}$ Entretanto, conforme observou Freitas, "além de substituir o agenciador no processo de seleção, também é preciso fiscalizar a contratação pelo próprio órgão do Governo, porque detectamos casos em que os operários eram trazidos de outro estado, fichados pelo Sine em Porto Velho e ingressavam como se fossem da região. Dessa forma, perdiam o direito à baixada e só podiam retornar para casa durante as férias, diminuindo os custos da empresa com transporte e aumentando o período em que estavam à disposição para trabalhar" (CUT Brasil, 2011g).
} 


\section{Questões para reflexão}

As revoltas e paralisações de março de 2011 nas obras do PAC alcançaram grande repercussão nacional. O esforço, aqui feito, de reconstituição dos acontecimentos, buscou situá-los com um foco nos casos de Jirau e Santo Antônio e na atuação sindical. Nosso objetivo final foi identificar as posições em disputa e propor questões sobre as potencialidades e os limites da ação sindical em tal contexto.

Projetos como esses, resultantes de investimentos do PAC, conforme evidenciam as cifras envolvidas, implicam grande importância econômica. Ao mesmo tempo, têm suscitado explosivos conflitos sociais - envolvendo os "atingidos" pelas barragens, os peões das obras de construção civil e os moradores das cidades do seu entorno - e questões ambientais com forte repercussão nacional e internacional, como a situação que envolveu a saída de Marina Silva do Governo. Associado a tudo isso, em cada episódio desses processos têm sido travadas batalhas entre os diversos sujeitos envolvidos que, por sua vez, compõem uma luta política mais ampla, referida aos destinos da sociedade brasileira - estão em questão o padrão de desenvolvimento a ser adotado no país, o modelo da relação Estado-sociedade-mercado, os arranjos de forças políticas que conformam os blocos no poder.

Foi sob tal contexto que entraram em cena os peões da construção civil, escancarando suas condições de trabalho e de permanência nos canteiros do PAC. Essa dimensão da realidade não compunha o discurso governamental enunciador do novo projeto desenvolvimentista do país, a não ser por meio de alguma sinalização para o que deve implicar em termos de crescimento econômico associado a desenvolvimento social. Muito menos, tal elemento esteve presente no discurso autolegitimador dos consórcios proprietários das obras em questão, sempre com uma dimensão social e ambiental incorporada (vejam-se os sites aqui indicados). No que se refere ao sindicalismo, seja em escala local, seja em escala nacional, uma combinação entre alguma atuação sobre tal realidade (incorporada no seu fazer próprio, cotidiano) e, na outra mão, uma certa adequação a uma normalidade institucional e a um enredamento em compromissos políticos mais amplos (trazidos particularmente com a configuração Lula e Dilma no Governo), situava-o como um elemento de mediação por excelência, ao mesmo tempo com alguma potencialidade e importantes limites.

A contundência dos acontecimentos, seja pela condição social vivida pelos peões, seja pela forma de luta que deles brotou, produziu inesperados, desconcertantes e indesejados deslocamentos (ou reposicionamentos) nos arranjos que conformavam as dinâmicas sociais antes estabelecidas em torno desses projetos. Um sujeito antes oculto emerge na cena, revelando 
o quão embrutecidas têm sido as condições que lhes são impostas nesse arranjo, revelando-se um tanto rudes no seu modo de agir, mas sobretudo escancarando o caráter contraditório, incoerente, superficial das práticas e principalmente dos discursos por parte dos sujeitos estrategicamente posicionados na referida cena. ${ }^{18}$ Nesse desarranjo-rearranjo de forças, os sentidos em disputa se mostram mais flagrantes à observação.

No que se refere ao sindicalismo, ficou evidente o estado de surpresa com que recebeu os acontecimentos. Após alguma vacilação, em um esforço imediato de evitar associar sua imagem ao radicalismo das revoltas, buscou legitimar-se como representante dos trabalhadores mobilizados. As reivindicações foram então sistematizadas, os processos de negociação se estabeleceram junto às autoridades governamentais e às empresas. Parte da radicalidade das condições denunciadas e das ações desencadeadas foi incorporado ao discurso sindical, ao mesmo tempo em que o sindicato buscou afirmar-se como canal de expressão e representante das demandas dos peões nos processos de negociação. Os saldos dos acontecimentos têm algo de conquista e, ao mesmo tempo, de reprodução das condições denunciadas.

Entrando em cena, em condições explosivas e inesperadas, os peões das obras do PAC se tornaram visíveis, nas condições que lhes são socialmente impostas e na sua capacidade de emergirem por conta própria: para a sociedade, que de tais dimensões da realidade social recebem raras e fragmentadas notícias); para o Governo, por demais preocupado com as obras em si e com os seus cronogramas de execução; e para os empresários, atentos, como tais, sobretudo aos lucros que podem extrair desses empreendimentos. Mas também tais acontecimentos, e as condições sociais que denunciam,

\footnotetext{
${ }^{18}$ Nos termos de Sardan (2005: 189, 199 e 200, respectivamente), são categorias-chave para pensar o desenvolvimento, especialmente em perspectiva local: "conflitos", "arena" e "grupos estratégicos". Quanto à noção de "conflito" adotada: "despite the fact that conflicts often reflect differences of position within of the social structure, we will need to bear in mind that individuals still retain some elbow room. The emergence, management and outcome of conflicts are by no means predetermined. Interpersonal or inter-group conflicts are not only signs of opposing 'objective' interests, they are also the by-product of personal strategies and of idiosyncratic phenomenon. Structural analysis must be completed by an analysis of strategies". Sobre "arena": "an arena, as we understand it, is a space in which real conflicts between interacting social actors occur around common stakes. It occurs in within a 'local space' [...] Arena has a greater descriptive content than field. And we prefer it. But it is of course not an explicative concept, just an exploratory one". No que se refere ao sentido de "grupos estratégicos": "[...] the "virtual' strategic group is a working hypothesis which help us to reflect on the convergence of certain individual strategies, from which we might deduce that the individuals in question have an identical position in face a given 'problem' [...] As opposed of classic sociological definitions of social groups, strategic groups (whether virtual or real) are not constructed once and for all and are not relevant to all types of problems: they vary according to the problem at hand, that is, according to local issues".
} 
se tornaram visíveis e presentes para o próprio mundo sindical. Os sindicatos locais, em alguma medida, incorporaram essa nova energia, revitalizando-se. Ao mesmo tempo, o fizeram buscando converter tal energia nos seus termos, domesticando as demandas de algum jeito. Essa redinamização da vida sindical local influenciou, inclusive por suas repercussões, a dinâmica sindical mais geral, aquela cujos atores mais relevantes são as centrais sindicais, confederações e federações. Uma outra escala de desdobramentos dos acontecimentos assim foi desencadeada - alguma da energia originalmente produzida foi passada adiante, em alguma medida reeditando o poder sindical de mobilização e dando-lhe maior visibilidade pública, ao mesmo tempo em que novas traduções foram sendo processadas, de modo a circunscrever as demandas, escancaradas originalmente e reelaboradas em seguida, para condições mais institucionalmente estabelecidas. Nesse âmbito, algumas cobranças foram feitas (por exemplo, condicionar financiamento público a contrapartidas sociais, no âmbito das obras do PAC) e alguns deslocamentos foram tentados (como o acordo tripartite, que implicaria em alterações quanto aos objetos contratados e ao teor político dos procedimentos adotados). Entretanto, sem maiores sucessos. A energia liberada na origem dos acontecimentos não resultou em mudanças institucionais, ao final desse ciclo de acontecimentos. Mas tiveram o mérito de pôr na mesa um critério, um parâmetro, uma perspectiva, que não estava presente senão por vias oblíquas, quase invisíveis. Embora sob limites, os espaços de ação, as posições dos atores nesses espaços e as dinâmicas daí resultantes sofreram deslocamentos. Foi o que buscamos apreender nesse estudo.

Quanto ao sindicalismo, só poderá jogar um papel mais decisivo quanto ao novo padrão de desenvolvimento que vem se estabelecendo no país ${ }^{19}$ se for capaz de canalizar, processar e potencializar as energias e demandas oriundas dos conflitos do trabalho, assumindo suas consequências políticas, reeditando-se assim como protagonista da cena política do país, conforme discutimos em Araújo e Véras (2011). Nos termos de Hyman (2001), se coloca o desafio de que o sindicalismo venha a poder articular, a um só tempo, estratégias focadas no mercado de trabalho, na sua inserção social mais ampla e na perspectiva de classe implicada na configuração

\footnotetext{
${ }_{19}$ Destacar o lugar do social no debate atual sobre a retomada da ideia-força do desenvolvimento requer dar um realce especial ao momento da política, assim como tomar esta para além da discussão sobre o papel do Estado. Para Boschi (2011: 16), "as diversas políticas que se busca colocar em prática mobilizam atores e interesses que enfrentam um jogo de estratégias, uma dinâmica que, por natureza, é incerta". Por outro lado, pôr em evidência a dimensão social do desenvolvimento, requer tratar com centralidade da problemática do trabalho referida à questão da cidadania: um desafio ao horizonte sindical.
} 
dos diversos interesses em disputa. Um desafio e tanto, quando pensamos no caso brasileiro, no qual apesar de vivenciar um momento de retomada do desenvolvimento precisa lidar sempre com um imenso passivo social, um significativo déficit de cidadania e persistentes limites na inserção sindical no mundo do trabalho.

Recebido a 08.10.2013

Aprovado para publicação a 07.03.2014

\section{Referências bibliográficas}

Aguirre, Basilia; Bianchi, Ana Maria (1989), "Reflexões sobre a organização do trabalho agrícola”, Revista de Economia Política, 9(1), jan-mar, 31-46.

Araújo, Angela; Véras, Roberto (2011), "El sindicalismo brasileño em La Era de Lula", Trabajo, 5(8), 83-112.

Banco Central do Brasil (2013), "Indicadores econômicos consolidados". Página consultada a 17.05.2013, em http://www.bcb.gov.br/?INDECO.

Brasil (2010), "Programa de Aceleração do Crescimento (PAC): balanço 4 anos (2007-2010)”. Página consultada a 27.06.2011, em http://www.brasil.gov. br/pac/relatorios/nacionais/11o-balanco-4-anos/parte-1/view.

Brasil (2012), "PAC 2”. Página consultada a 28.04.2014, em http://www.pac.gov.br/.

Blog do Planalto (2011), "O governo vai entrar firme na tentativa de antecipar crises em obras federais”, 29.03.2011. Página consultada a 18.07.2011, em http://blog.planalto.gov. br/o-governo-vai-entrar-firme-na-tentativa-de-antecipar-crises-em-obras-federais/.

Boschi, Renato (2011), "Introdução: instituições, trajetórias e desenvolvimento - uma discussão a partir da América Latina”, in Renato Boschi (org.), Variedades de capitalismo, política e desenvolvimento na América Latina. Belo Horizonte: Editora UFMG, 07-30.

Bresser-Pereira, Luiz Carlos (2006), "O novo desenvolvimentismo e a ortodoxia convencional”, São Paulo em Perspectiva, 20(3), 5-24.

Carta Capital (2011a), "Trabalhadores de Santo Antonio aceitam propostas de construtora e aprovam volta ao serviço”, 05.04.2011. Página consultada a 18.07.2011, em http://www.cartacapital.com.br/politica/trabalhadores-de-santo-antonio-aceitam-propostas-de-construtora-e-aprovam-volta-ao-servico/.

Carta Capital (2011b), “Fator Jirau”, 26.04.2011. Página consultada a 18.07.2011, em http://www.cartacapital.com.br/sociedade/fator-jirau/.

Chaú, Marilena (1997), Cultura e democracia: o discurso competente e outras falas. São Paulo: Cortez Editora.

CNTM - Confederação Nacional dos Trabalhadores Metalúrgicos (2011), "Nota da Força sobre condições de trabalho em Jirau", 18.03.2011. Página consultada a 19.07.2011, em http://www.cntm.org.br/materia.asp?id_CON=7142. 
Cockell, Fernanda (2008), "Da enxada à colher de pedreiro: trajetórias de vulnerabilidade social na construção civil”. Tese de Doutorado em Engenharia de Produção - Programa de Pós-Graduação em Engenharia de Produção da Universidade Federal de São Carlos, Brasil.

Cockell, Fernanda; Perticarrari, Daniel (2010), “Contratos de boca: a institucionalização da precariedade na construção civil”, Caderno CRH, 23(60), 633-653.

Costa, Luciano Rodrigues (2013), Trabalbadores em construção: mercado de trabalho, redes sociais e qualificações na construção civil. Curitiba: Editora CRV.

CUT Brasil (2011a), "Processo de negociação segue em Jirau e Santo Antônio", 22.03.2011. Página consultada a 15.07.2011, em http://www.cut.org.br/destaques/ 20470/processo-de-negociacao-segue-em-jirau-e-santo-antonio.

CUT Brasil (2011b), “CUT lidera acordo em Rondônia”, 22.03.2011. Página consultada a 15.07.2011, em http://www.cut.org.br/destaques/20472/cut-lidera-acordoem-rondonia.

CUT Brasil (2011c), "Devemos aprofundar o debate para não agirmos sempre de forma paliativa, afirma mediador da CUT em Rondônia”, 01.04.2011. Página consultada a 15.07.2011, em http://www.cut.org.br/destaques/20511/devemos-aprofundar-o-debate-para-nao-agirmos-sempre-de-forma-paliativa-afirma-mediador-da-cut-em-rondonia.

CUT Brasil (2011d), "CUT em Rondônia: construção das usinas envolve histórias de exploração sexual e provoca caos no serviço público”, 10.04.2011. Página consultada a 15.07.2011, em http://www.cut.org.br/destaques/20544/cut-em-rondonia-construcao-das-usinas-envolve-historias-de-exploracao-sexual-e-provoca-caos-no-servico-publico.

CUT Brasil (2011e), "CUT na luta em Rondônia: trabalhadores de Jirau aprovam acordo e assembleia dá início a campanha-salarial”, 11.04.2011. Página consultada a 15.07.2011, em http://www.cut.org.br/destaques/20546/cut-na-luta-em-rondonia-trabalhadores-de-jirau-aprovam-acordo-e-assembleia-da-inicio-a-campanha-salarial.

CUT Brasil (2011f), "Em Rondônia, trabalhadores arrancam aumento real acima da média e mudança na baixada”, 17.04.2011. Página consultada a 15.07.2011, em http://www.cut.org.br/destaques/20567/em-rondonia-trabalhadores-arrancam-aumento-real-acima-da-media-e-mudanca-na-baixada-en.

CUT Brasil (2011g), “'Precisamos rediscutir o modelo, para que Belo Monte não seja uma Jirau no Pará', diz secretário cutista”, 18.04.2011. Página consultada a 15.07.2011, em http://www.cut.org.br/destaques/20573/precisamos-rediscutir-o-modelo-para-que-belo-monte-nao-seja-uma-jirau-no-para-diz-secretario-cutista.

CUT Brasil (2011h), "Justiça de Rondônia reconhece Sticcero como legítimo representante dos trabalhadores”, 02.05.2011. Página consultada a 15.07.2011, em http:// www.cut.org.br/destaques/20624/justica-de-rondonia-reconhece-sticcero-como-legitimo-representante-dos-trabalhadores. 
CUT Brasil (2011i), "Depois de encontro com Dilma, Sticcero e MAB se reúnem com Gilberto-Carvalho para cobrar ações nas usinas em Rondônia”, 12.07.2011. Página consultada a 15.07.2011, em http://cut.org.br/destaques/20957/depois-de-encontro-com-dilma-sticcero-e-mab-se-reunem-com-gilberto-carvalho-para-cobra r-acoes-nas-usinas-em-rondonia.

CUT Brasil (2011j), "Após audiência com Ministério do Trabalho e Camargo Corrêa, CUT visita hoje obras de Jirau e Santo Antônio”, 01.04.2011. Página consultada a 28.04.2014, em http://www.cut.org.br/destaques/20466/apos-audiencia-com-ministerio-do-trabalho-e-camargo-correa-cut-visita-hoje-obras-de-ji rau-e-santo-antonio.

CUT Brasil (2011k), "Jirau: desfecho positivo das negociaçes não resolve todos os problemas, alerta Vagner Freitas”, 01.04.2011. Página consultada a 28.04.2014, em http://www.cut.org.br/destaques/20511/devemos-aprofundar-o-debate-para-nao-agirmos-sempre-de-forma-paliativa-afirma-mediador-da-cut-em-rondonia.

DIEESE (2001), Os trabalhadores e a reestruturação produtiva na construção civil brasileira. São Paulo: DIEESE.

Diniz, Eli (2011), "O contexto internacional e a retomada do debate sobre desenvolvimento no Brasil contemporâneo (2000/2010)”, DADOS - Revista de Ciências Sociais, 54(4), 493-531.

Draibe, Sônia; Riesco, Manuel (2011), "Estados de Bem-Estar Social e estratégias de desenvolvimento na América Latina: um novo desenvolvimentismo em gestação?", Sociologias, 13(27), 220-254.

Esterci, Neide (1987), “O conflito no Araguaia: peões e posseiros contra a grande empresa”. Petrópolis: Vozes.

Farah, Marta Ferreira Santos (1996), Processo de trabalbo na construção babitacional: tradição e mudança. São Paulo: Annablume.

Folba.com (2011a), "Consórcio de Jirau recua e não há mais prazo para retomar obra", 18.03.2011. Página consultada a 19.07.2011, em http://www1.folha.uol.com.br/mercado/ 890867-consorcio-de-jirau-recua-e-nao-ha-mais-prazo-para-retomar-obra.shtml.

Folha.com (2011b), "Obra de Jirau será retomada na segunda-feira, diz Consórcio", 18.03.2011. Página consultada a 19.07.2011, em http://m.folha.uol.com.br/mercado/ 890810-obra-de-jirau-sera-retomada-na-segunda-feira-diz-consorcio.html.

Fontes, Edilza (2003), “O peão de trecho e o peão de casa: identidade operária entre os trabalhadores da construção civil de Barcarena no canteiro de obras da Albras/ Alunorte”, Novos Caernos NAEA, 6(1), 65-82.

Guedes, André Dumans (2011), "O Trecho, as mães e os papéis - movimentos e durações no Norte de Goiás”. Tese de Doutorado, Museu Nacional/ Universidade Federal do Rio de Janeiro, Brasil.

Heredia, Beatriz (1989), Formas de dominação e espaço social: a modernização da agroindústria canavieira em Alagoas. São Paulo: Marco Zero/Brasília: MCT/CNPq. 
Hyman, Richard (2001), Understanding european trade unionism. London: Sage.

IBGE - Instituto Brasileiro de Geografia e Estatística (2011), "Sinopse do Censo Demográfico 2010”. Brasília. Página consultada a 15.05.2012, em http://www. censo2010.ibge.gov.br/sinopse/.

Isto É Brasil (2011), "Sindicatos contra o PAC", 25.03.2011. Página consultada a 19.07.2011, em http://www.istoe.com.br/reportagens/130264_SINDICATOS $+\mathrm{CONTRA}+\mathrm{O}+\mathrm{PAC}$.

Isto É Dinheiro (2011), "BNDES diz que manterá verba para Jirau e Santo Antônio", 21.03.2011. Página consultada a 19.07.2011, em http://www.istoedinheiro.com. br/noticias/52295_BNDES+DIZ+QUE+MANTERA+VERBA+PARA+JIRAU+E +SANTO+ANTONIO.

Krein, Dari; Santos, Anselmo dos; Nunes, Bartira (2011), "Trabalho no governo Lula: avanços e contradições”, Revista da Abet, X(2), 30-55.

Kupfer, David (2007), “Tem PPP no PPI do PAC”, Jornal Valor Econômico. Página consultada a 17.05.2012, em http://www.ie.ufrj.br/aparte/pdfs/kupfer070207.pdf.

Leitão, Karina (2009), “A dimensão territorial do Programa de Aceleração do Crescimento: um estudo sobre o PAC no Estado do Pará e o lugar que ele reserva à Amazônia no desenvolvimento do país”. Tese de Doutorado apresentada à Universidade de São Paulo, Brasil.

MAB - Movimento dos Atingidos por Barragens (2011), "Nota do Movimento dos Atingidos por Barragens - MAB, sobre revolta dos operários na Usina Hidroelétrica de Jirau", 17.03.2011. Página consultada a 19.07.2011, em http://www.mabnacional. org.br/?q=noticia/nota-do-movimento-dos-atingidos-por-barragens-mab-sobre-revolta-dos-oper-rios-na-usina-hidre.

MPT - Ministério Público do Trabalho (2011), "MPT de Rondônia atua para garantir os direitos de trabalhadores da Usina de Jirau (RO)”, 21.03.2011. Página consultada a 28.04.2014, em http://mpt.jusbrasil.com.br/noticias/2612615/mpt-de-rondonia-atua-para-garantir-os-direitos-de-trabalhadores-da-usina-de-jirau-ro.

Moret, Artur; Guerra, Sinclair (2009), "Hidrelétricas no Rio Madeira: reflexões sobre impactos ambientais e sociais", Revista OIDLES, 3(7), dez.

O Globo (2012), "Projetos bilionários do PAC têm atraso de até 54 meses", 02.04.2012. Página consultada a 15.05.2012, em http://oglobo.globo.com/pais/projetos-bilionarios-do-pac-tem-atraso-de-ate-54-meses-4470948.

Offe, Claus (1984), Contradictions of the Welfare State. Organização de John Keane. London: Hutchinson.

Oliva, Aloízio (2010), “As bases do novo desenvolvimentismo no Brasil: análise do governo Lula (2003-2010)”. Tese de Doutorado apresentado à Universidade Estadual de Campinas, Brasil.

O Rondinense (2011), “Nota à Imprensa - STICCERO”, 18.03.2011. Página consultada a 17.07.2011, em http://www.orondoniense.com.br/textos.asp?cd=31111. 
Pêgo, Bolívar; Campos Neto, Carlos (2008), “O PAC e o setor elétrico: desafios para o abastecimento do mercado brasileiro (2007-2010)”, Texto para Discussão, Brasília: Ipea, n. ${ }^{\circ} 1329$.

Pochmann, Marcio (2001), A década dos mitos: o novo modelo econômico e a crise do trabalho no Brasil. São Paulo: Contexto.

Pochmann, Marcio (2012), "Novo desenvolvimentismo como resposta à crise global", in Ipea - Instituto de Pesquisa Económica Aplicada (org.), Panorama das comunicações e das telecomunicações no Brasil-2011/2012, Volume 1. Brasília: Ipea/Socicom, 15-28.

Rainho, Luís (1980), Os peões do grande ABC. Petrópolis: Vozes.

Ridenti, Marcelo (2008), "Desenvolvimentismo: o retorno", Anais do 36. Encontro da Associação Nacional dos Centros de Pós-Graduação em Economia, Salvador, Brasil, 9 a 12 de dezembro de 2008. Página consultada a 17.05.2012, em http://www. espacoacademico.com.br/092/92ridenti.pdf.

Rodrigues, Taíla; Salvador, Evilásio (2011), “As implicações do Programa de Aceleração do Crescimento (PAC) nas políticas sociais”, SER Social, 13(28), 129-156. Página consultada a 16.05.2011, em: http://seer.bce.unb.br/index. php/SER_Social/article/view/5624/4672.

Rondoniagora.com (2011), "Nota à imprensa - Camargo Corrêa”, 19.03.2011. Página consultada a 17.07.2011, em http://www.rondoniagora.com/noticias/nota-a-imprensa---camargo-correa-2011-03-19.htm.

Rondonia Dinâmica (2011), "Após quatro meses dos conflitos, problemas em Jirau persistem”, 13.07.2011. Página consultada a 17.07.2011, em http://www.rondoniadinamica.com/arquivo/apos-quatro-meses-dos-conflitos-problemas-em-jirau-persistem-,27161.shtml.

Sardan, Jean-Pierre Olivier de (2005), Anthropology and Development: Understand Contemporary Social Change. London/New York: Zed Books.

Sicsú, João; Paula, Luiz de; Michel, Renaut (2007), "Por que novo-desenvolvimentismo?”, Revista de Economia Política, 27(4), 507-524.

UOL Notícias (2011a), "CUT vai propor ao governo câmara tripartite para acompanhar obras do PAC”, 29.03.2011. Página consultada a 16.07.2011, em http://noticias.uol. com.br/cotidiano/ultimas-noticias/2011/03/29/cut-vai-propor-ao-governo-camara-tripartite-para-acompanhar-obras-do-pac.htm.

UOL Notícias (2011b), "170 mil trabalhadores da construção civil cruzaram os braços em março, aponta Dieese”, 04.04.2011. Página consultada a 16.07.2011, em http://noticias.uol.com.br/politica/ultimas-noticias/2011/04/04/mais-de-170-mil-trabalhadores-da-construcao-civil-cruzaram-os-bracos-em-marco-aponta-dieese.htm.

Veja (2011), "Gilberto Carvalho tenta acordo contra paralisação de obras do PAC”, 29.03.2011. Página consultada a 17.07.2011, em http://veja.abril.com.br/noticia/ brasil/gilberto-carvalho-tenta-acordo-contra-paralisacao-de-obras-do-pac/imprimir. 
136 | Roberto Véras

Véras, Roberto (2004), “Governo Lula, pacto social e acção sindical”, in Elísio Estanque; A. Casimiro Ferreira; Hermes Augusto Costa; Leonardo Mello e Silva; Roberto Véras (orgs.), Relações laborais e sindicalismo em mudança: Portugal, Brasil e o contexto transnacional. Coimbra: Quarteto, 45-70.

Véras, Roberto (2011), Sindicalismo e democracia no Brasil: do novo sindicalismo ao sindicato cidadão. São Paulo: Annablume.

Waterman, Peter (2008), "Social Movement Unionism in Question: Contribution to a Symposium”, Employee Responsibilities and Rights Journal, 20(4), 303-308. 